\title{
Modulation of Neuronal Firing Mode in Cat and Guinea Pig LGNd by Histamine: Possible Cellular Mechanisms of Histaminergic Control of Arousal
}

\author{
David A. McCormick and Anne Williamson \\ Section of Neurobiology, Yale University School of Medicine, New Haven, Connecticut 06510
}

The thalamus is innervated by histaminergic fibers presumably arising from neurons in the tuberomammillary nucleus of the hypothalamus. The possible function of this histaminergic projection was addressed through investigation of the cellular actions of histamine on guinea pig and cat dorsal lateral geniculate (LGNd) relay neurons maintained as a slice in vitro. Local application of histamine to LGNd relay neurons resulted in a slow depolarization that was associated with a decrease in membrane conductance and was blocked by the $H_{1}$-antagonists pyrilamine, triprolidine, or diphenhydramine. Current versus voltage relationships revealed that the slow depolarization was associated with an inward current that reversed near $E_{k}$, indicating that it was due to a decrease in a potassium current. The slow depolarizing response to histamine was occluded by maximal activation of the slow depolarizing responses resulting from stimulation of $\alpha_{1}$-adrenergic or muscarinic receptors, suggesting that they are all mediated by reduction in the same potassium current and/ or alteration of a common second messenger. In the presence of $\mathrm{H}_{1}$-receptor antagonists, application of histamine resulted in a small depolarization that was associated with a marked increase in apparent membrane conductance. Voltage-clamp recordings revealed that this response was associated with enhancement of the hyperpolarization-activated cation current $I_{n}$. This response to histamine was blocked by local or bath application of the $\mathrm{H}_{2}$-antagonists cimetidine or tiotidine. The functional consequences of these actions of histamine were addressed with extracellular and intracellular recordings in guinea pig and cat LGNd relay neurons. Extracellular recordings in cat LGNd revealed the occurrence of highly regular 1-4 Hz rhythmic burst discharges. Application of histamine halted rhythmic bursting and replaced it with a prolonged period of single-splke activity. Intracellular recordings indicate that the histamine-induced switch in firing mode is due largely to the slow depolarizing response mediated by $\mathrm{H}_{1}$-receptors, but is also facilitated by the enhancement of $I_{h}$ mediated by $\mathrm{H}_{2}$-receptors. These postsynaptic actions indicate that increased activity in the tuberomammillary histaminergic system may result in a switch

Received Apr. 1, 1991; revised May 7, 1991; accepted May 13, 1991.

This work was supported by the National Institute for Neurological Disorders and Stroke, the Klingenstein Fund, the Sloan Fuundation, and the Jacobs Javits Center for Neuroscience.

Correspondence should be addressed to David A. McCormick, Section of Neurobiology, SHM C303, Yalc University School of Medicine, 333 Cedar Street, New Haven, CT 06510.

Copyright (C) 1991 Society for Neuroscience $0270-6474 / 91 / 113188-10 \$ 05.00 / 0$ of thalamic neuronal activity from rhythmic burst firing to single-spike activity and thereby promote the accurate transmission and processing of sensory information and cognition.

Immunocytochemical localization of histamine (HA) in the CNS of a number of species including guinea pigs, cats, and humans has revealed a dense network of HA-containing axons that appear to arise from a relatively small number of neurons in the tuberomammillary nucleus of the hypothalamus (Lin et al., 1986; Airaksinen and Panula, 1988; Panula et al., 1989, 1990). In the thalamus, these axons are distributed throughout the specific relay nuclei, reticular nucleus, and the intralaminar nuclei (Airaksinen and Panula, 1988). Autoradiographic localization of $\mathrm{H}_{1}$-histaminergic receptors in the guinea pig reveals a high density of these receptors over regions of the thalamus, including the LGN (Bouthenet et al., 1988), while localization of $\mathrm{H}_{2}$ histaminergic receptors in the rat reveals a moderate to low density in the thalamus (Ruat et al., 1990). The presence of this histaminergic innervation of the thalamus implies that HA may act as a neurotransmitter or neuromodulator in this brain region, although to our knowledge the electrophysiological actions of HA on thalamic relay neurons have not previously been addressed.

Recent electrophysiological experiments have emphasized the central role of the thalamus in the generation of synchronizcd rhythms in the forebrain during drowsiness and slow-wave sleep and the replacement of these rhythms with tonic activity and increased responsiveness to receptive field stimuli during periods of waking and attentiveness (Steriade and Deschênes, 1984; Steriade and Llinás, 1988; McCormick, 1989). The central control of the aroused and attentive state, and its antithesis, drowsiness and sleep, appears to involve histaminergic mechanisms. Systemic administration of antihistamines is often associated with drowsiness, sleep, and synchronization of the electroencephalogram, effects mediated through block of $\mathrm{H}_{1}$-receptors (Douglas, 1980; Wauquier et al., 1981; Lin et al., 1988). Similarly, intraventricular administration of HA leads to prolonged periods of arousal that can be blocked by the administration of $\mathrm{H}_{1}$-antagonists (Monneir et al., 1970; Kalivas, 1982; Tasaka et al., 1989). Finally, extracellular recordings from presumed histaminergic neurons during the slecp-wakc cycle reveal that the average firing rate of these cells increases in anticipation of increases in arousal, and decreases in anticipation of drowsiness or sleep (Vanni-Mercier et al., 1984; Reiner and McGeer, 1987). Together, these data suggest that HA-releasing neurons in the hypothalamus may exhibit a potent and important modulatory control over thalamocortical activity. 
We have recently demonstrated that three different neurotransmitters, ACh, noradrenaline (NA), and 5-HT, can alter the state of neuronal activity exhibited by thalamocortical relay neurons in vitro by modulating specific ionic conductances. Activation of muscarinic receptors with $\mathrm{ACh}$ or of $\alpha_{1}$-adrenoceptors with NA results in a substantial slow depolarization that results from the suppression of a potassium conductance (McCormick and Prince, 1987, 1988). In contrast, activation of $\beta$-adrenoceptors or serotonergic receptors enhances the hyperpolarization-activated cation current $I_{h}$, an effect that appears to be mediated through stimulation of adenylyl cyclase (Pape and McCormick, 1989; McCormick and Pape, 1990b). Together, these two actions depolarize the membrane potential of thalamocortical relay cells into or near the threshold for generation of single-spike activity and potently block the ability of these cells to exhibit rhythmic burst firing (McCormick and Prince, 1988; McCormick, 1989; McCormick and Pape, 1990a,b). This ability to determine the firing mode of thalamocortical relay neurons may allow these three neurotransmitters to control important features of neuronal and synaptic processing in the forebrain. Here, we investigate the possibility that HA may have similar actions in the thalamus and that it may also contribute to the determination of firing mode of thalamocortical relay cells.

\section{Materials and Methods}

Our methods for preparation of thalamic slices and recording from lateral geniculate relay neurons werc similar to those published previously (McCormick and Prince, 1987; McCormick and Pape, 1990a). Male or female adult Hartley guinea pigs were deeply anesthetized with sodium pentobarbital $(35 \mathrm{mg} / \mathrm{kg}$, i.p.) and killed by decapitation. Four adult cats were preanesthetized with ketamine $(25 \mathrm{mg} / \mathrm{kg}$, i.m. $)$, very deeply anesthetized with sodium pentobarbital $(25-35 \mathrm{mg} / \mathrm{kg}$, i.v.), and killed by decapitation. In both cases, the region of brain containing the dorsal lateral geniculate nucleus (LGNd) was removed, placed in cold $\left(5^{\circ} \mathrm{C}\right)$ bathing solution, and sectioned as $400-\mu \mathrm{m}$-thick slices on a Vibratome (Lancer Corporation). Thalamic slices were placed in an interface-style recording chamber (Fine Science Tools) and allowed to recover for at least $2 \mathrm{hr}$ before recording commenced. The bathing medium contained (in $\mathrm{mM}$ ) NaCl, $124 ; \mathrm{KCl}, 2.5 ; \mathrm{MgSO}_{4}, 1.2 ; \mathrm{NaH}_{2} \mathrm{PO}_{4}$, 1.25; $\mathrm{CaCl}_{2}, 2 ; \mathrm{NaHCO}_{3}, 26$; dextrose, 10 ; and was aerated with $95 \%$ $\mathrm{O}_{2}, 5 \% \mathrm{CO}_{2}$ to a final pII of 7.4 .

Agonists were dissolved in the bathing medium and were generally applied with the pressure-pulse technique in which a brief pulse of pressure (10-100 msec, 200-350 $\mathrm{kPa}$ ) to a broken micropipette (tip diameter, $2-10 \mu \mathrm{m}$ ) was used to extrude volumes of 2-20 pl. Antagonists were applied either locally or through addition to the bathing medium. Prior to application of antagonists, HA was applied two to four times to insure a stable response to this agonist. Local application of drugs has the advantage that the onset of action is quick and the duration shortened. Therefore, repeated applications of agonists can be performed in a short time period. However, this technique has the disadvantage that the final concentration of the drug in the bath is unknown. In experiments in which we have used both local and bath applications of agonists and antagonists to study the same response, we have found that application of a drug by local application is roughly equivalent to a 10-fold lower concentration of the same drug in the bath (McCormick and Wang, 1991). Extracellular single-unit recordings were obtained with tungsten microelectrodes, while intracellular recordings were obtained with microelectrodes formed from "thin wall" glass (World Precision Instruments) on a Sutter Instruments P-80/PC micropipette puller, filled with $4 \mathrm{M} \mathrm{K}$-acetate, with a final resistance of 35-50 M 2 .

Single-electrode voltage clamp was performed with an Axoclamp-2A amplifier connected to an IBM AT-style computer operating pCLAMP software (Axon Instruments). Switching frequencies were generally 3$4 \mathrm{kHz}$, and gain was between 0.5 and $1.0 \mathrm{nA} / \mathrm{mV}$. During current clamp, bridge balance was continuously monitored and adjusted, while during voltage clamp, headstage output was continuously monitored to insure adequate settling time. Current versus voltage $(I-V)$ plots were obtained by steadily hyperpolarizing the neurons from a holding potential of -55 $\mathrm{mV}$ to between -120 and $-140 \mathrm{mV}$ over a period of 5-10 sec and measuring the amount of current required to do so. From 3 to 10 individual current traces obtained during voltage-clamp were averaged to reduce noise. Activation curves for the hyperpolarization-activated cation current $I_{h}$ were constructed through analysis of tail currents at approximately $-60 \mathrm{mV}$ after stepping to various hyperpolarized membrane potentials in cat LGNd neurons. Sufficient time (e.g., 100-200 $\mathrm{msec}$ ) was allowed after stepping to $-60 \mathrm{mV}$ to allow the capacitive and transient inward currents (e.g., $I_{T}$ ) to pass so as not to contaminate the measurement of $I_{h}$.

\section{Results}

Intracellular recordings were obtained from neurons in the LGNd of the guinea pig $(n=58)$ and cat $(n=12)$. A representative sample of 20 of these neurons had an average resting membrane potential of $-66 \pm 3 \mathrm{mV}( \pm \mathrm{SD})$, input resistance of $47+11$ $\mathrm{M} \Omega$, and spike amplitude of $92 \pm 6 \mathrm{mV}$. The electrophysiological properties of these neurons were typical for thalamocortical relay neurons, and we therefore refer to them as such (Jahnsen and Llinás, 1984a,b; Steriade and Deschênes, 1984).

Application of HA (300-500 $\mu \mathrm{M}$ in micropipette) to the surface of the slice while recording from either guinea pig or cat LGNd relay neurons typically resulted in a mixture of two basic responses: a slow depolarization that could reach threshold for the generation of action potentials (Fig. $1 A$ ) and that was associated with a decrease in apparent input conductance (Fig. $1 B$ ), or a small depolarization that was associated with a substantial increase in apparent input conductance (Fig. $1 C, D$ ). Comparison of the responses to HA between cat and guinea pig LGNd revealed both responses in both species, although the response characterized by a small depolarization and an increase in conductance was substantially smaller in guinea pig than in cat LGNd neurons (not shown). Local application (10 $\mu \mathrm{M}$ in micropipette) of the $\mathrm{H}_{1}$-antagonists pyrilamine $(n=6)$, triprolidine $(n=3)$, or diphenhydramine $(n=4)$ blocked the slow depolarizing response and typically uncovered the second type of response to HA, the increase in apparent input conductance (Fig. 2). The slow depolarization and decrease in membrane conductance response to HA persisted in the presence of high concentrations of the $\mathrm{H}_{2}$-antagonists tiotidine $(5 \mu \mathrm{M} ; n=3$ ) or cimetidine ( $10 \mu \mathrm{M} ; n=4)$. Together, these results indicate that the slow depolarizing response is mediated by the $\mathrm{H}_{1}$-subtype of histaminergic receptor. Application of HA in the presence of pyrilamine ( $1 \mu \mathrm{M}$ in bath) resulted in the small depolarization and large increase in conductance response in nearly all guinea pig and cat neurons tested (e.g., Fig. 3B). Local application of the $\mathrm{H}_{2}$ antagonists cimetidine $(n=5)$ or tiotidine $(n=3)(10$ $\mu \mathrm{M}$ in micropipette) blocked this response, indicating that it is mediated by the $\mathrm{H}_{2}$-subclass of histaminergic receptor (Fig. 2; Haaksma et al., 1990).

Although previous investigations of cortical and hippocampal pyramidal cells have shown that stimulation of $\mathrm{H}_{2}$-receptors can block spike frequency adaptation through reduction of the slow $\mathrm{Ca}^{2+}$-activated $\mathrm{K}^{+}$current $I_{\mathrm{AHP}}$ (Haas and Greene, 1986; McCormick and Williamson, 1989), this is unlikely to be a significant effect in LGNd relay neurons, since these cells display little spike frequency adaptation (Jahnsen and Llinás, 1984a,b; McCormick and Feeser, 1990) or significant slow $\mathrm{Ca}^{2+}$-activated $\mathrm{K}^{+}$currents (D. A. McCormick and A. Williamson, unpublished observations).

The possibility that HA was causing a slow depolarization in 
A
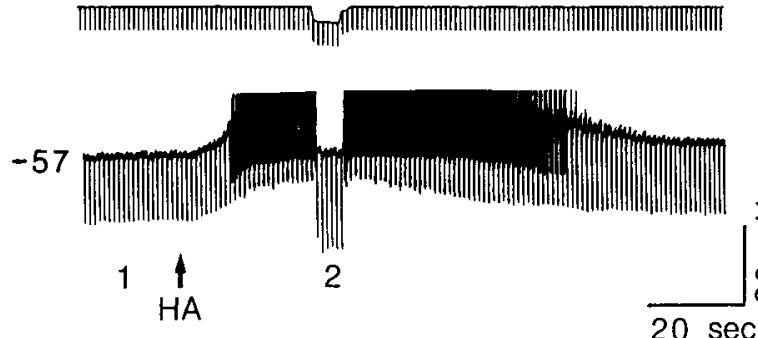

B

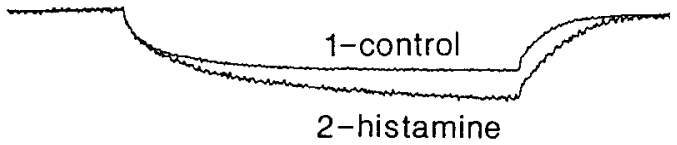

C
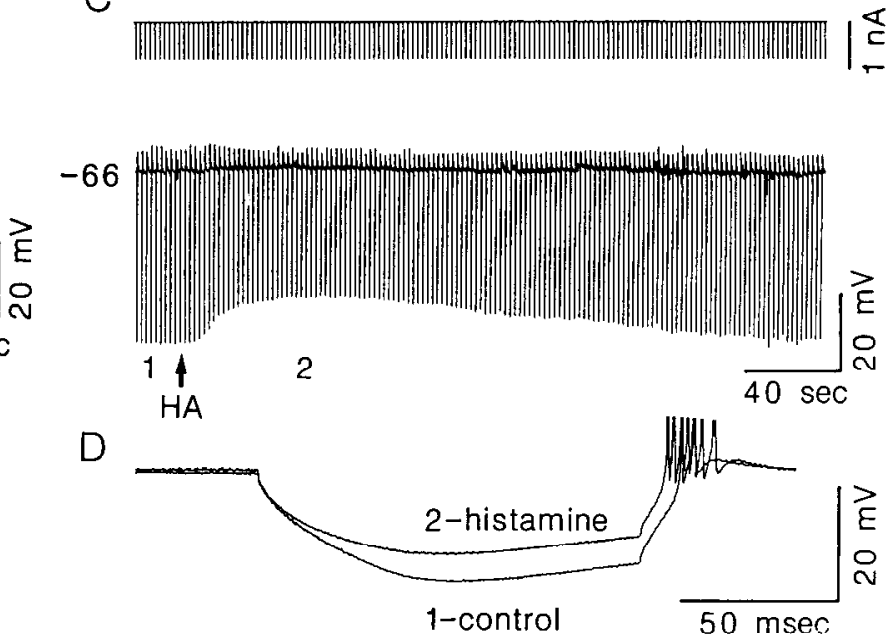

Figure 1. Two distinct responses elicited by HA in relay neurons of the LGNd. Application of HA to this guinea pig LGNd neuron after depolarization of the cell to $-57 \mathrm{mV}$ with the intracellular injection of current resulted in a slow depolarizing response $(A)$. Compensation for this slow depolarization with the intracellular injection of current revealed a substantial decrease in apparent membrane conductance and a lengthening of the membrane time constant $(A, B)$. The electrotonic response of the neuron to hyperpolarizing current pulses before (control) and during compensation for the slow depolarizing response with intracellular injection of current $(H A)$ is shown in $B$. An additional response that was found in a small percentage of neurons in normal solution, or in nearly all neurons after pharmacological block of $\mathrm{H}_{1}$-receptors, is shown in $C$. Application of HA in these cells resulted in a small (1-3 mV) depolarization that was associated with a substantial increase in apparent membrane conductance at hyperpolarized membrane potentials $(C, D)$. The cell in $A$ and $B$ was a guinea pig LGNd neuron, while the cell in $C$ and $D$ was from the cat LGNd.

thalamic relay neurons through activation of muscarinic or $\alpha_{1}-$ adrenergic receptors (McCormick and Prince, 1987, 1988) was discounted by the finding that this HA response was not blocked by including the $\alpha_{1}$-antagonist prazosin $(1-10 \mu \mathrm{M})$ or the muscarinic antagonist scopolamine $(1-10 \mu \mathrm{M})$ in the bathing me$\operatorname{dium}(n=7)$. The possibility that HA was causing the second type of response, namely the small depolarization and increase in membrane conductance, through stimulation of $\beta$-adrenergic or serotonergic receptors (Pape and McCormick, 1989; McCormick and Pape, 1990b) was also discounted by the inability of the $\beta$-adrenoceptor antagonist propranolol $(50 \mu \mathrm{M} ; n=4)$ or the serotonergic receptor antagonist methysergide (10 $\mu \mathrm{M} ; n=$ 4) to block this response to HA.

\section{Block of synaptic transmission with tetrodotoxin}

The possibility that HA was causing these two different types of responses through release of another neuroactive substance was tested by blocking synaptic transmission by local application of the sodium channel poison tetrodotoxin (TTX; $10 \mu \mathrm{M}$ ). Block of electrically evoked synaptic transmission failed to block either the slow depolarizing response to $\mathrm{HA}$ mediated by $\mathrm{H}_{1}-$ receptors $(n=5$; Fig. $3 A)$ or the increase in apparent input conductance mediated by $\mathrm{H}_{2}$-receptors $(n=5$; Fig. $3 B)$. The amplitudes of these responses were, however, sometimes reduced, particularly in cases in which the application of TTX reduced the apparent input resistance of the neuron. This effect of TTX may be explained either by reduction of apparent input resistance of the cell resulting from block of the persistent $\mathrm{Na}^{+}$ current, or through an enhancing effect of the persistant $\mathrm{Na}^{+}$ current on the ability of dendritic depolarizations to affect the soma (from which our recordings presumably originate). In any event, these results suggest that these two responses to HA are mediated by histaminergic receptors located directly on the LGNd neurons recorded.
Nonadditivity of histaminergic, noradrenergic, and cholinergic slow depolarizations

The striking resemblance of the two different types of responses to $\mathrm{HA}$ in relation to those obtained after application of NA, ACh, and 5-HT (McCormick and Prince, 1987, 1988; Pape and McCormick, 1989) indicated that they may be mediated by similar cellular and ionic mechanisms. If there were convergence of these neurotransmitters onto the same response, then they should exhibit the property of nonadditivity, in which the maximal activation of one set of receptors blocks the response to activation of the other through occlusion, where maximal activation by an agonist is defined as a response in which further application of this agonist does not increase the amplitude of the response, although the duration may be lengthened (e.g., Andrade et al., 1986). Indeed, we found that maximal activation of histaminergic receptors with local application of HA $(0.5 \mathrm{~mm}$ in micropipette) completely blocked or substantially reduced the slow depolarizing response to NA $(0.5 \mathrm{~mm})$, even after compensation of the slow depolarization with the intracellular injection of current $(n=4$; Fig. $4 A)$. Likewise, the maximal activation of adrenoceptors with NA blocked the response to HA $(n=4$; Fig. $4 B)$. Finally, maximal activation of the slow depolarizing response to HA occluded the slow depolarizing response to the muscarinic agonist acetyl- $\beta$-methylcholine ( $\mathrm{MCh}$; 5 mм in micropipette), but did not alter the hyperpolarizing response to this agonist $(n=4$; Fig. $4 C)$. An additional finding of interest from these investigations was that maximal activation of any of these three receptors from resting membrane potential (e.g., $-65 \mathrm{mV}$ ) was typically just sufficient to bring the membrane potential either to, or within $5 \mathrm{mV}$ of, firing threshold (not shown).

These data indicate that activation of $\mathrm{H}_{1}-, \alpha_{1}$-adrenergic, and muscarinic receptors may all rcsult in a slow depolarization through the same cellular mechanisms (see also McCormick, 
A

Control

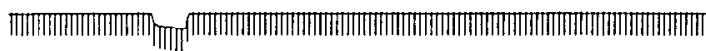

$-57$

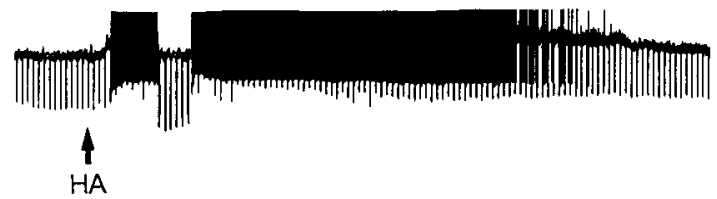

$\mathrm{B}$

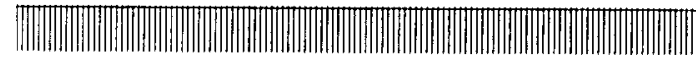

$-67$

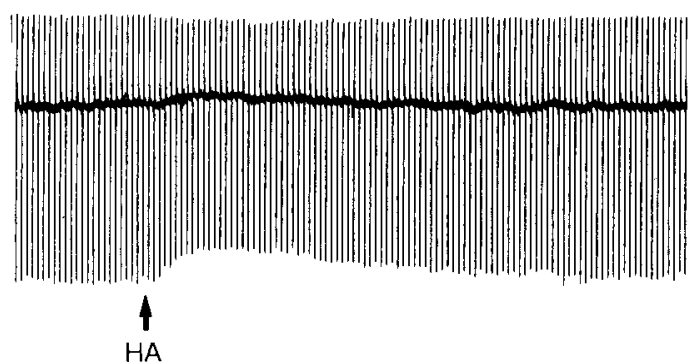

Triprolidine
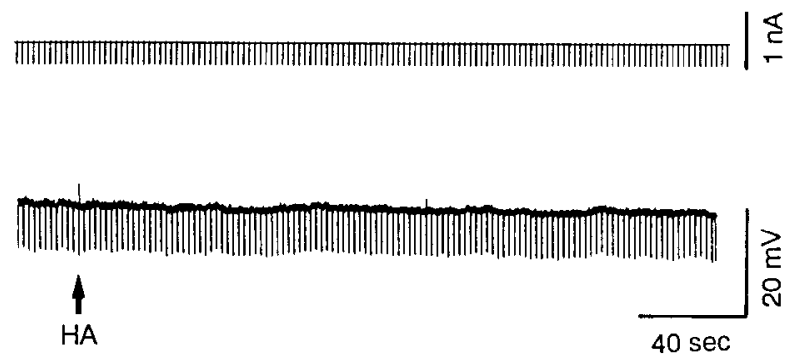

Triprolidine+Tiotidine
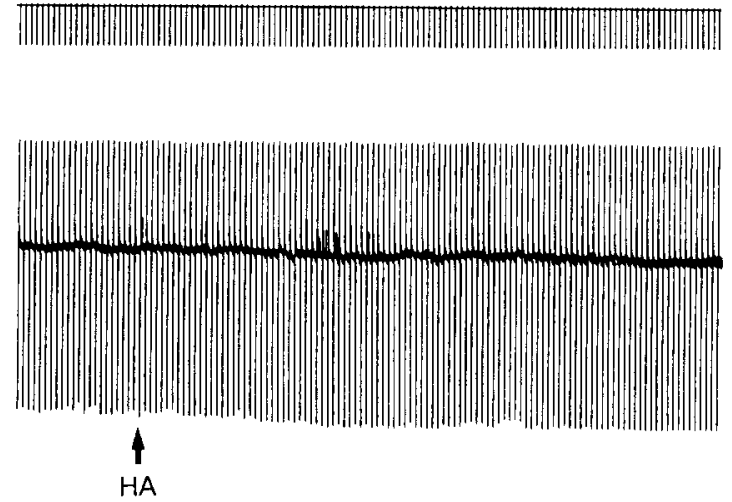

Figure 2. HA modulates thalamic neurons through both $\mathrm{H}_{1}$ - and $\mathrm{H}_{2}$-histaminergic receptors. Application of $\mathrm{HA}$ to this guinea pig LGNd neuron after tonic depolarizing to $-57 \mathrm{mV}$ with the intracellular injection of current results in a slow depolarizing response and the generation of action potentials. Local application of the $\mathrm{H}_{1}$-antagonist triprolidine (10 $\mu \mathrm{M}$ in micropipette) results in a complete block of this response. $B$, Application of $\mathrm{HA}$ at resting membrane potential $(-67 \mathrm{mV})$ after application of triprolidine results in the small depolarization and increase in membrane conductance response. Local application of the $\mathrm{H}_{2}$-antagonist tiotidine (10 $\mu \mathrm{M}$ in micropipette) blocks this response.

1989). Since the slow depolarizing response to NA and MCh appears to result from the suppression of a potassium current that is active at all membrane potentials (McCormick and Prince, 1987,1988 ), these results suggest that a similar ionic mechanism may underlie the depolarizing response to HA.

\section{Ionic basis of slow depolarizing response to $\mathrm{HA}$}

The ionic basis of the slow depolarizing response was examined by obtaining current versus voltage $(I-V)$ relationships before and during the action of HA through the use of the singleelectrode voltage-clamp technique. The slow depolarizing response mediated by $\mathrm{H}_{1}$-receptors was isolated from the other major response to $\mathrm{HA}$ through including the $\mathrm{H}_{2}$-antagonist cimetidine $(10 \mu \mathrm{M})$ in the bathing medium and/or through local application of $\mathrm{Cs}^{+}(10-20 \mathrm{~mm}$ in micropipette) to block the $\mathrm{H}$-current (McCormick and Pape, 1990a). Block of $I_{h}$ with $\mathrm{Cs}^{+}$ was necessary for two reasons: (1) $I_{h}$ is the dominant current in thalamocortical relay neurons hyperpolarized below resting membrane potential, and its presence significantly reduces the ability to control the membrane potential in voltage clamp (McCormick and Pape, 1990a); and (2) HA can cause large shifts in the voltage sensitivity of $I_{h}$ through the activation of $\mathrm{H}_{2}$ receptors (see below).

Under these conditions, application of HA resulted in a slow depolarization that was always associated with a decrease in apparent input conductance (not shown). In voltage clamp, this response appeared as an inward current associated with a decrease in the slope of the $I-V$ relation, indicating a decrease in apparent input conductance. The average reversal potential was $-106( \pm 2.6) \mathrm{mV}$ in $2.5 \mathrm{~mm}\left[\mathrm{~K}^{+}\right]_{\circ}(n=4$; Fig. $5 A, B)$, implying that this response is due to a decrease in a potassium current Subtracting the $I-V^{\prime}$ relationships obtained at the peak of the HA response from those obtained prior to application of HA revealed the voltage sensitivity of the current suppressed by HA. Interestingly, these plots indicate that this current is not particularly voltage sensitive in that its amplitude was linearly related to the driving force upon $\mathrm{K}^{+}\left(V_{m}-E_{k}\right.$; Fig. $\left.5 B\right)$. The linearity of this current assures that it will contribute substantially to the "leak" conductance of the membrane potential, even at rest. Therefore, for convenience, we have termed this $\mathrm{K}^{+}$current $I_{\mathrm{KL}}$.

\section{Histaminergic enhancement of $\mathrm{I}_{\mathrm{h}}$}

Application of HA in some LGNd neurons in normal solution, and in nearly all neurons after block of $\mathbf{H}_{1}$-receptors, resulted in a small depolarization and large increase in apparent input conductance, as mentioned above (Fig. 1B). This response presents many similarities to those to stimulation of $\beta$-adrenergic and serotonergic receptors, which we have recently shown to be due to an enhancement of the hyperpolarization-activated cation current $I_{h}$ (Pape and McCormick, 1989; McCormick and Pape, 1990b). We therefore tested the possibility, through the use of single-electrode voltage clamp, that HA may also enhance $I_{h}$.

Application of $\mathrm{HA}$ after the pharmacological block of $\mathrm{H}_{1}$ receptors resulted in a voltage-dependent alteration in the $I-V$ 
A
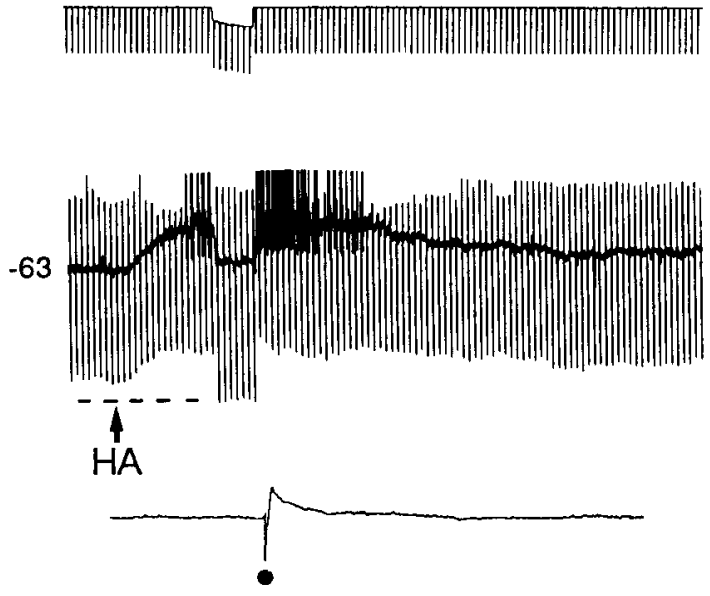

B


$\operatorname{TTX}$
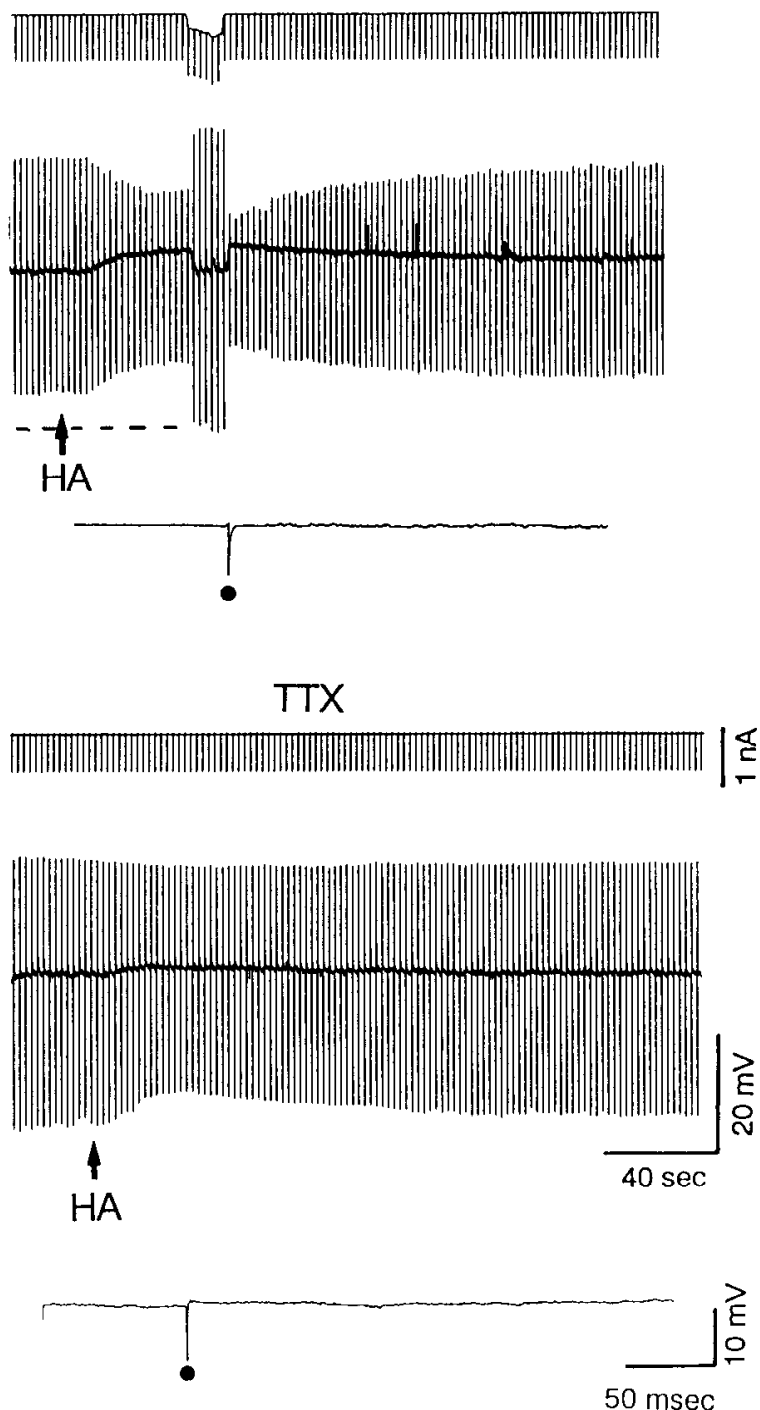

Figure 3. Histaminergic responses are direct postsynaptic actions. A, Application of HA to this guinea pig LGNd cell depolarized with current injection to $-66 \mathrm{mV}$ results in the typical slow depolarizing response. Local application of TTX blocked electrical stimulation-evoked postsynaptic potentials, indicating that synaptic transmission had been blocked $(A$, bottom trace). Under these circumstances, the slow depolarizing response to HA persisted $(A, T T X) . B$, Similarly, block of synaptic transmission with TTX did not block the small depolarizing and increase in membrane conductance response to $\mathrm{HA}$ in the presence of the $\mathrm{H}_{1}$-antagonist pyrilamine.

relation such that there was an inward shift at membrane potentials negative to approximately -60 to $-65 \mathrm{mV}$ (Fig. 5C). Plot of the amplitude of this inward shift in the $I-V$ relation versus membrane potential indicated that it was strongly voltage dependent, increasing with increasing degrees of hyperpolarization at membrane potentials between approximately -60 and $-85 \mathrm{mV}$ (Fig. $5 D$ ). At more negative membrane potentials, this effect of HA lessened (Fig. 5D) and eventually fell to zero (not shown), presumably owing to the fact that the effect is mediated by a shift in the activation curve for $I_{h}$ with little change in its maximal amplitude (see below). In this manner, the decrease in size of the HA response at negative membrane potentials is due to an approach to the maximal activation of $I_{h}$ (see Fig. $7 A$ ). However, the voltage dependency of this effect is likely to be inaccurate to an unknown degrec duc to the limitations of the single-electrode voltage-clamp technique.
To examine the effect of HA on $I_{h}$ directly, this current was elicited by holding the cell at approximately $-60 \mathrm{mV}$ and stepping to various levels of hyperpolarization for $2-5 \mathrm{sec}$. These hyperpolarizing steps lead to increasing degrees of activation of $I_{h}$ (Fig. 6). Upon return of the membrane potential to the holding potential, prolonged inward tail currents were elicited, which represent the deactivation or "turning off" of $I_{h}$ (Figs. 6, 7). Application of HA resulted in a pronounced enhancement of $I_{h}$ with a small increase in the instantaneous "leak" conductance (Fig. 6). This increase in "leak" conductance, which was difficult to measure due to interference from the transient capacitative currents, may have resulted from an increase in the amount of $\mathrm{H}$-conductance active at the holding potential $(-59 \mathrm{mV}$; see Fig. 7A). The enhancement of $I_{h}$ was also associated with an increase in the rate of activation of this current (Fig. 6), as we have previously shown in detail for $\beta$-noradrenergic and sero- 

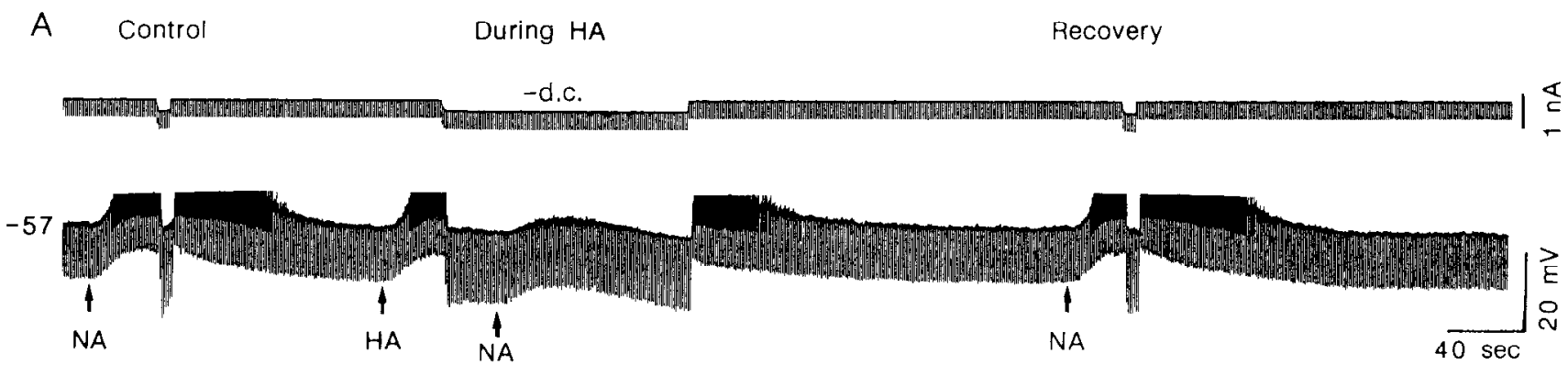

B Control

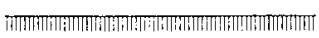

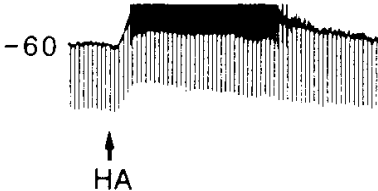

C

Control

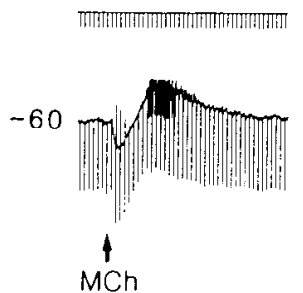

During NA
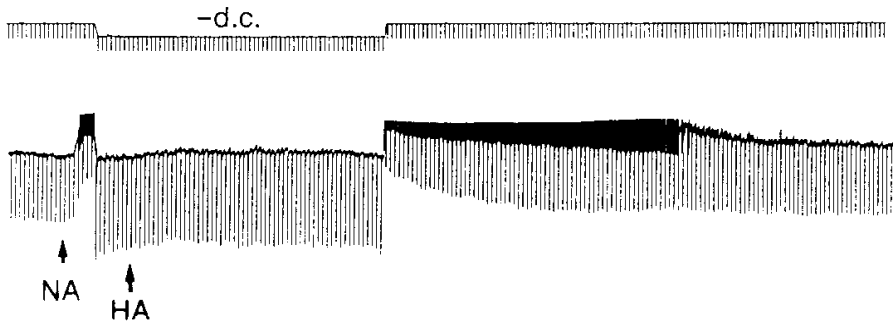

HA

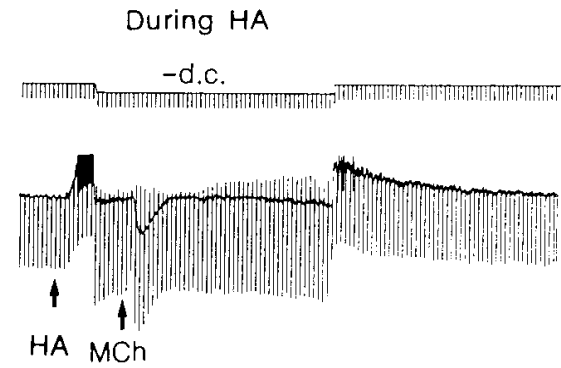

Recovery

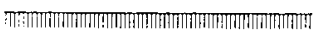

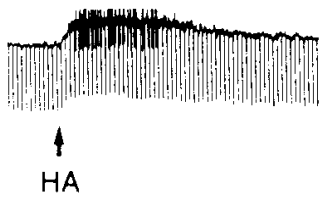

Recovery

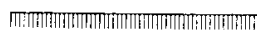

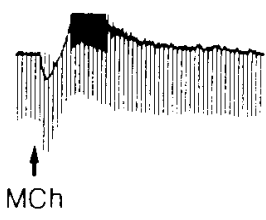

Figure 4. Nonadditivity of HA, NA, and muscarinic responses. Application of NA to a cell at $-57 \mathrm{mV}$ results in the typical slow depolarizing response that is associated with a decrease in apparent membrane conductance. Application of a maximal dose of $\mathrm{HA}$ also results in a slow depolarization. Compensation for the HA-induced slow depolarization with the intracellular injection of current $(-d . c$.$) also reveals a substantial$ decrease in apparent input conductance. Application of NA at this point results in only a small response $(A, D u r i n g H A)$. The NA response recovers as the HA-induced slow depolarization declines (NA, Recovery). Similarly, maximal application of NA occludes the response to HA (B), and maximal application of HA occludes the slow depolarizing, but not the hyperpolarizing, response to the muscarinic agonist $\mathrm{MCh}(C)$. Action potentials have been truncated for illustrative purposes.

toninergic enhancement of $I_{h}$ (McCormick and Pape, 1990b). The data in Figures $5 \mathrm{C}$ and 6 suggest that activation of $\mathrm{H}_{2}$ histaminergic receptors may result in an enhancement of $I_{h}$ at membrane potentials between at least -55 and $-93 \mathrm{mV}$. However, this result is limited in interpretation due to the limitations inherent to the single-electrode voltage-clamp technique, particularly during the activation of large currents such as $I_{h}$. Therefore, to circumvent these problems partially, we constructed activation curves before and during this response to HA through the analysis of the $I_{h}$ tail currents (Fig. 7B). This technique has the advantage that the current is always measured near resting membrane potential and that the amplitude of $I_{h}$ during the period of measurement is significantly reduced. In this manner, analysis of tail currents revealed that the activation of $\mathrm{H}_{2}$-histaminergic receptors is associated with a shift of the activation curve to more positive membrane potentials by an average of $7.6 \mathrm{mV}( \pm 2.5 \mathrm{mV} ; n=4$; Fig. 7). Both the increase in rate of activation and the positive shift of the activation curve indicate that the main effect of $\mathrm{HA}$ through $\mathrm{H}_{2}$-receptors is to alter the voltage-sensitive properties of $I_{h}$ so that it activates at more depolarized membrane potentials, although our data at present are insufficient to rule out an additional increase in the maximal amplitude of $I_{h}$.

\section{Functional consequences of $H A$ responses}

The functional consequences of the actions of $H A$ in the LGNd were examined with both intracellular and extracellular recording techniques. Extracellular single-unit recordings $(n=10)$ in layers $\mathrm{A}$ and $\mathrm{A} 1$ of the cat $\mathrm{LGN}$ revealed that most, but not all, presumed relay neurons spontaneously and rhythmically burst at a rate of between 0.5 and $4 \mathrm{~Hz}$ (Fig. 8). Each burst in this rhythmic activity contained between two and six action potentials with an interspike frequency of between 300 and $500 \mathrm{~Hz}$ (Fig. $8 B$ ). We have previously reported that this slow, rhythmic burst firing results from the occurrence of low-threshold $\mathrm{Ca}^{2+}$ spikes, which themselves are triggered by the hyperpolarizationactivated cation current $I_{h}$ (McCormick and Pape, 1990a). Application of HA during spontaneous rhythmic bursting resulted in a potent block of this activity in all neurons and its replacement by the occurrence of single spike discharges in most $(n=$ 7). The discharge frequency of the single-spike activity gradually increased up to frequencies of $1-20 \mathrm{~Hz}$, and then decreased until 

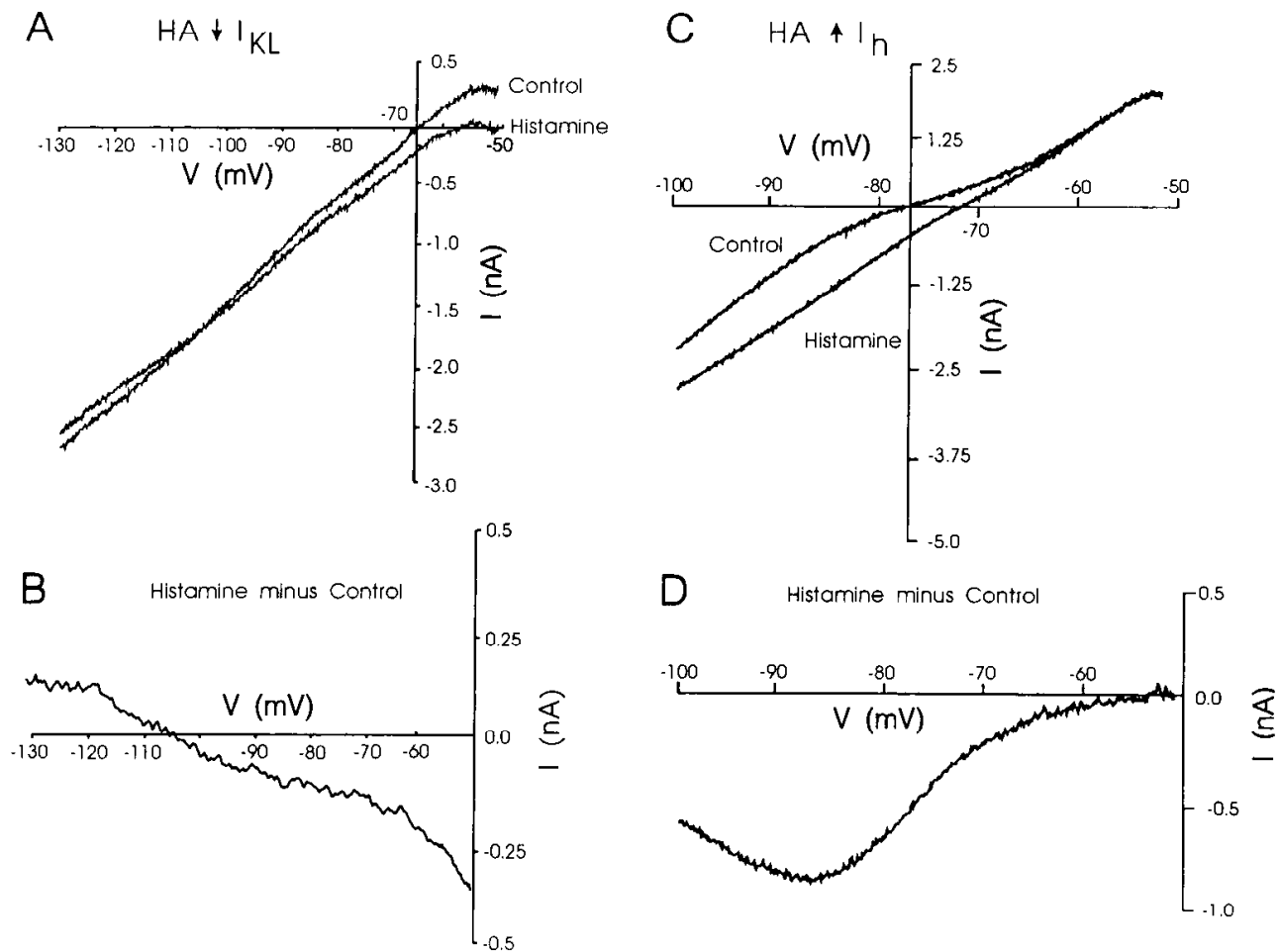

Figure 5. Current versus voltage ( $I-V$ ) relationships revealing the two actions of HA. $A, I-V$ relationships obtained before (Control) and after local application of HA reveal a decrease in apparent input conductance and an inward current that reverses polarity at approximately - $105 \mathrm{mV}$. $B$, Subtracting the $I-V$ relation obtained after HA from that obtained under control conditions reveals that the current that was blocked varies in a relatively linear manner with membrane potential. Together, these results indicate that HA is blocking a relatively linear $\mathrm{K}^{+}$current $\left(I_{\mathrm{KL}}\right)$ that contributes substantially to the normal "leak" membrane conductance. $I-V$ relations in this cell were obtained after the $\mathrm{H}$-current had been completely blocked through the local application of $\mathrm{Cs}^{+}(20 \mathrm{~mm}$ in micropipette). $C$, Application of HA to a cat LGNd cell results in a marked enhancement of the $H$-current. $I-V$ relations obtained after the local application of HA reveal an increase in input conductance in the hyperpolarizing range. $D$, Subtracting the normal $I-V$ relation from that obtained in $H A$ reveals the voltage dependence of this action of $H A$. $H A$ is found to result in a voltage-dependent inward current that is active at membrane potentials below approximately $-60 \mathrm{mV}$.

the neuron became silent. After 1-2 min, spontaneous rhythmic burst firing reappeared (Fig. 8). Although the frequency of this rhythmic burst firing was at first lower than normal, it gradually returned to baseline rates (not shown). These results indicate that HA has the capability of completely switching the firing mode of LGNd relay neurons from the rhythmic burst firing mode to the single-spike mode of action potential generation. Although we have not yet recorded this switch from rhythmic burst firing to single-spike activity intracellularly in response to $\mathrm{HA}$, presumably it arises from the histaminergic-induced slow depolarization that can depolarize these neurons the $10-20 \mathrm{mV}$ required to switch from the rhythmic burst mode to the singlespike mode of action potential generation (see Figs. $1 A$, 3; McCormick and Pape, 1990a).

The shift from sleep to waking is associated not only with an abolition of slow rhythmic burst firing and the appearance of single-spike activity, but also with an abolition of rebound burst discharges after large IPSPs and the enhancement of responsiveness to sensory evoked EPSPs (Livingstone and Hubel, 1981; Steriade and Llinás, 1988). The possibility that these changes in responsiveness of IGNd relay neurons may result in part through the actions of HA was examined in guinea pig and cat LGNd neurons. The effect of HA on rebound burst discharges and depolarizing inputs was investigated through the injection of hyperpolarizing and depolarizing current pulses (Fig. 9). The amplitude of these pulses was adjusted such that a rebound $\mathrm{Ca}^{2+}$ spike was generated after the hyperpolarizing current pulse and was of sufficient amplitude to result in the generation of action potentials (Fig. 9A,B), while the depolarizing current pulse was just subthreshold for doing so (Fig. $9 A, B$ ). Application of HA under these conditions resulted in a slow depolarization, a marked enhancement of the response to the depolarizing current pulse, and an equally marked reduction in the rebound $\mathrm{Ca}^{2+}$ spike following the hyperpolarizing current pulse (Fig. 9A,C). These effects appear to occur in large part through depolarization of the membrane potential, since hyperpolarization back to the pre-HA membrane potential typically reinstated the rebound burst response following a hyperpolarization and prevented the depolarizing current pulse from generating a train of action potentials (Fig. 9A,D). Similarly, after recovery from the HA-induced response, depolarization of the membrane with intracellular current injection to the potential reached at the peak of the HA response also resulted in abolition of rebound burst discharges and the promotion of single-spike activity (Fig. 9A,E).

The functional consequences of shifts in $I_{h}$ activation curve by HA were investigated either in LGNd neurons that exhibited no appreciable depolarizing response, or after block of $\mathrm{H}_{1}$-receptors by including pyrilamine or triprolidine $(1 \mu \mathrm{M})$ in the bathing medium $(n=7)$. Application of HA in these circumstances resulted in a small depolarization and a marked decrease in response to hyperpolarizing current pulses (Fig. 10), which subsequently resulted in a marked decrease in the amplitude of the rebound $\mathrm{Ca}^{2+}$ spike and associated burst of fast action potentials (Fig. 10). Increasing the amplitude of the hyperpolar- 
A

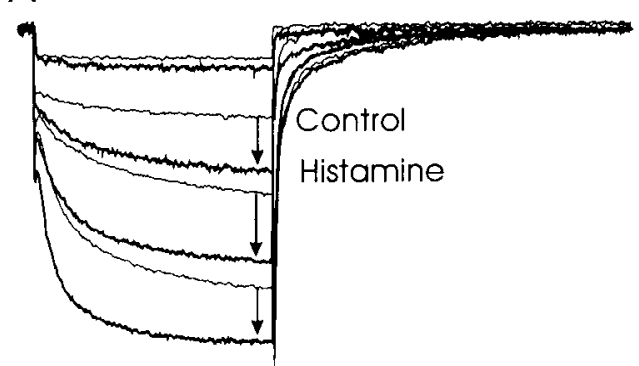

B
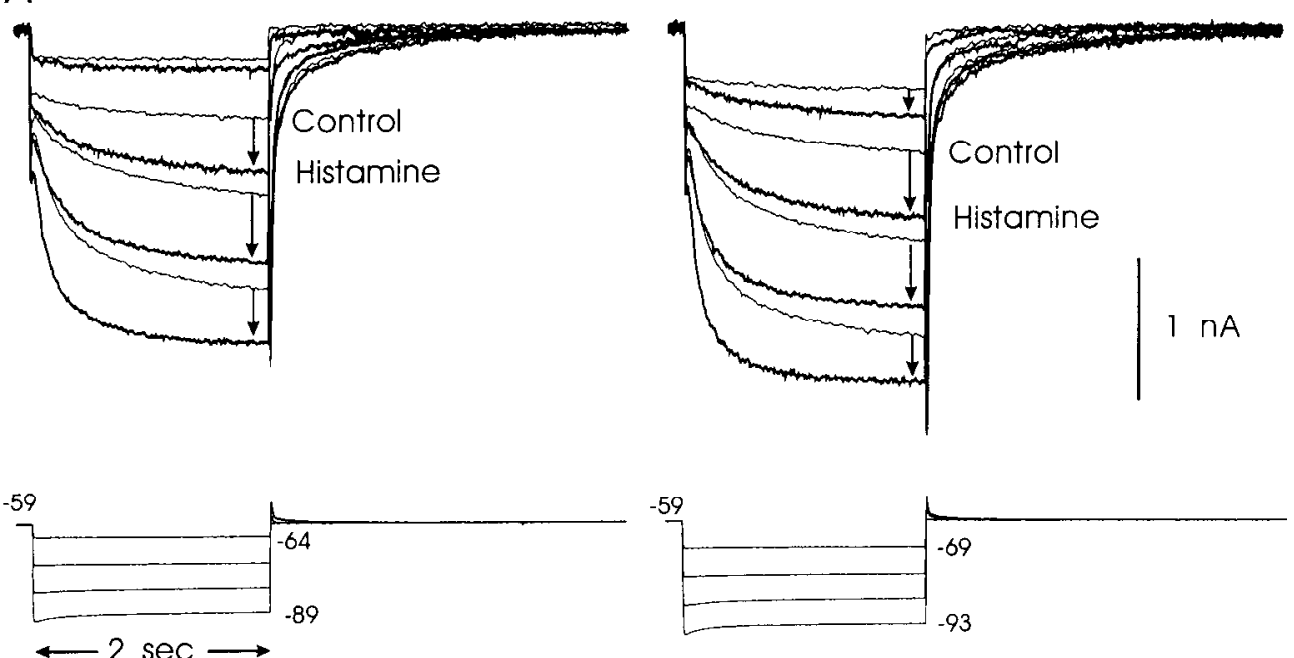

Figure 6. HA enhances a hyperpolarization-activated cation current. Application of hyperpolarizing voltage steps ( $2 \mathrm{sec}$ duration, $5 \mathrm{mV}$ increments) from a holding potential of $-59 \mathrm{mV}$ reveals the time- and voltage-dependent inward current known as $I_{h}(A, B)$. Application of $\mathrm{HA}$ results in a marked enhancement of $I_{h}$ with less effect on the instantaneous leak current. Data traces were separated into two sets for clarity. Traces in $A$ were obtained from four steps ranging from -64 to -89 $\mathrm{mV}$, while those in $B$ range from -69 to $-93 \mathrm{mV}$. Currents obtained after application of HA are plotted as a darker line, and the arrows indicate the current traces obtained before and after $\mathrm{HA}$ at the same membrane potential $(A, B)$. Analysis of tail currents from these traces is presented in Figure 7. Data were obtained from a cat LGNd neuron in lamina $\mathrm{A}$. izing current pulse so as to match the voltage deviation generated prior to $\mathrm{HA}$ application reinstated the full $\mathrm{Ca}^{2+}$ spikemediated burst of action potentials, indicating that $\mathrm{HA}$ is not directly blocking the burst response (not shown). In contrast to the reduction in response to hyperpolarizing current pulses, the occurrence of single-spike activity was facilitated, presumably resulting from the small slow depolarization (Fig. 10). Indeed, compensation for the depolarization with the intracellular injection of current typically reduced the response of the neuron to the depolarizing current pulse back to, or less than, control levels, presumably as a result of the increase in membrane conductance (not shown).

These results indicate that $\mathrm{HA}$ can potently antagonize the generation of rhythmic burst firing and promote the occurrence of single-spike activity both through depolarization of the neuron by reduction of a potassium current, $I_{K L}$, and through enhancement of the hyperpolarization-activated cation current, $I_{h}$.

\section{Discussion}

The thalamus receives a moderate to dense innervation of axons that are immunohistochemically positive for the presence of HA and that presumably arise from histaminergic cell bodies located in the tuberomammillary nucleus of the hypothalamus (Airaksinen and Panula, 1988). In addition, the guinea pig thalamus also contains a high density of $\mathrm{H}_{1}$ - and a moderate density of $\mathrm{H}_{2}$-histaminergic receptors (Bouthenet et al., 1988; Ruat et al., 1990). These results suggest that HA may act as a neurotransmitter in the thalamus, although to our knowledge, the electrophysiological and functional actions of HA in this brain region have not previously been addressed. Our results illustrate that HA can cause at least two distinct postsynaptic responses in thalamic relay neurons: a large $(5-20 \mathrm{mV})$ slow depolarization associated with a decrease in apparent input conductance mediated by $\mathrm{H}_{1}$-receptors, and a small depolarization associated with an increase in apparent input conductance mediated by $\mathrm{H}_{2}$-receptors. The slow depolarizing response appears to be mediated by a decrease in a potassium current, since this response reverses polarity at the equilibrium potential for $\mathrm{K}^{+}$and is nonadditive with the slow depolarizing responses to muscarinic and $\alpha_{1}$-adrenergic receptor stimulation, both of which we have previously shown to be mediated by decreases in membrane $\mathrm{K}^{+}$ conductance through ion substitution experiments (McCormick and Prince, 1987, 1988). Examination of current versus voltage $(I-V)$ relationships obtained prior to and during the slow depolarizing response indicates that the $\mathrm{K}^{+}$current that is sup-
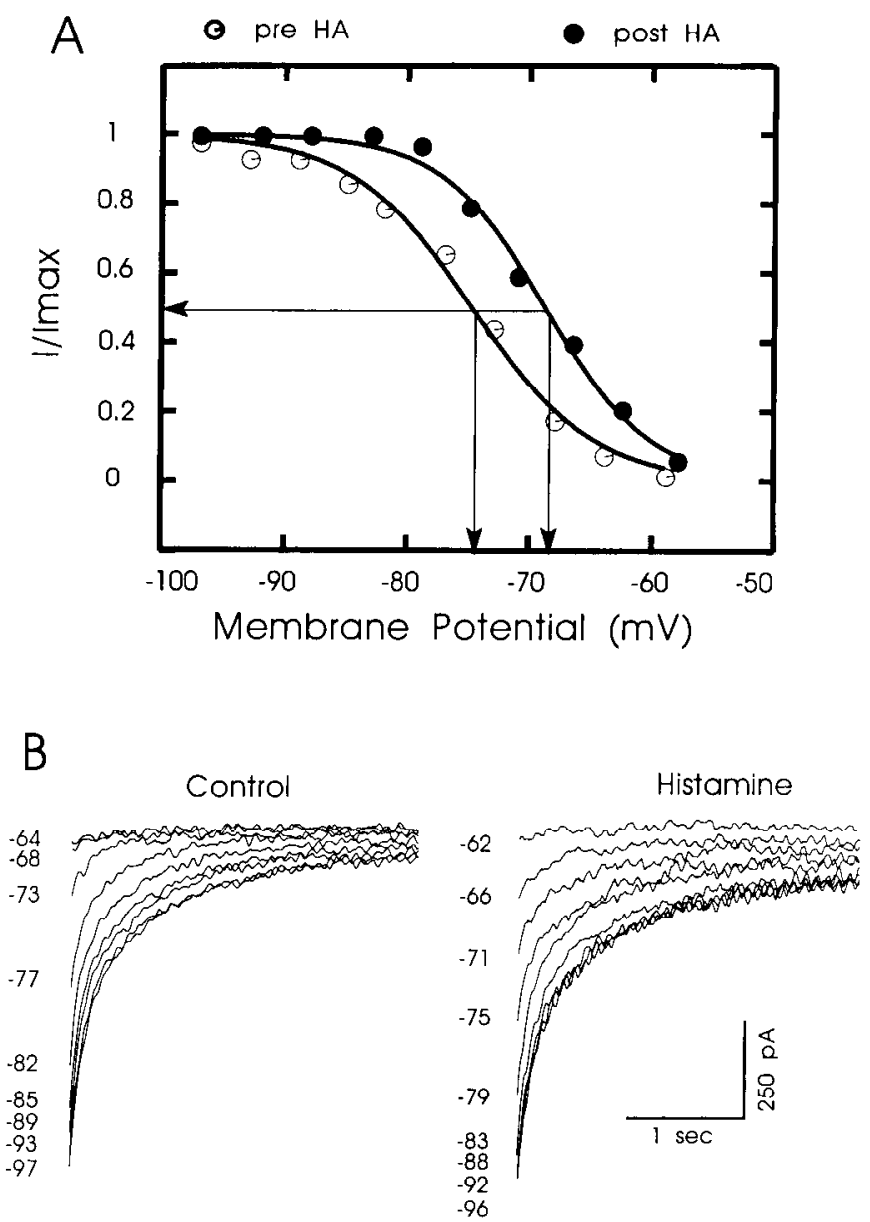

Figure 7. HA enhances $I_{h}$ through a shift in its activation curve. Plot of the activation curve of $I_{h}(A)$ through analysis of tail currents $(B)$ before and after application of HA reveals that the enhancement of $I_{h}$ is the result of a shift in the activation curve to more positive membrane potentials by approximately $6 \mathrm{mV}$. Tail currents were obtained from the cell shown in Figure 6. 
Figure 8. Application of HA to rhythmically bursting LGNd relay cells results in an abolition of burst firing and the occurrence of single-spike activity. $A$, Extracellular recording from a cat LGNd neuron revealed spontaneous rhythmic burst firing at a rate of 2-3 $\mathrm{Hz}$. Each vertical line represents a highfrequency burst of three to six action potentials. One such burst of action potentials is expanded in $B$ for detail. Application of HA results in a sudden abolition of the rhythmic burst firing that is followed by single-spike activity after an intervening period of silence. This single-spike activity is expanded for dctail in $B$. Complete recovery from this action of HA was obtained after approximately $1-2 \min (A)$.
A

Rhythmic bursting

Single spike firing

Rhythmic bursting
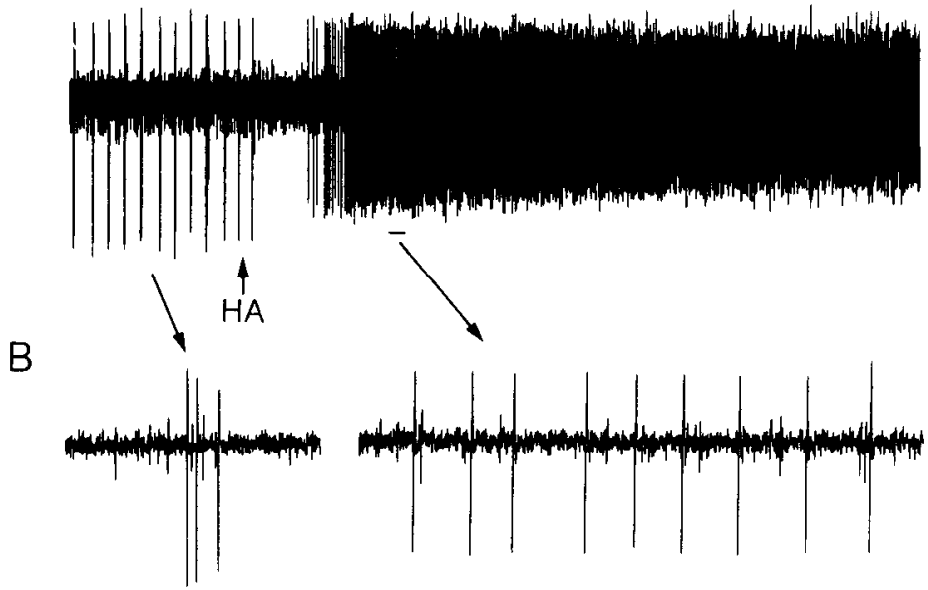
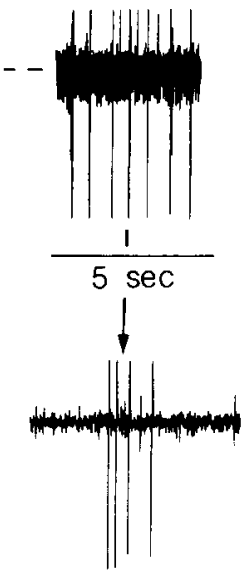

$\overline{50 \mathrm{msec}}$

pressed by activation of $\mathrm{H}_{1}$-receptors varies in a relatively linear manner with the driving force $\left(V-E_{k}\right)$ on $\mathrm{K}^{+}$ions in the presence of $\mathrm{Cs}^{+}$, a result that is identical to that which we have obtained for the slow depolarizing responses activated by muscarinic and $\alpha_{1}$-adrenergic receptors in LGNd relay neurons (D. A. McCormick, unpublished observations) and for $\alpha_{1}$-adrenergic and $5-\mathrm{HT}_{2}$ serotonergic receptors in the thalamic reticular nucleus (McCormick and Wang, 1991). The relatively linear nature of this current, assuming that this linearity is not due to extracellular application of $\mathrm{Cs}^{+}$, will allow activation of $\mathrm{H}_{1}$ receptors to depolarize thalamic neurons at all membrane potentials, although the amplitude of this depolarization will, of course, become greater at more depolarized membrane potentials due to the increased driving force on $\mathrm{K}^{+}$. The secondmessenger system, if any, through which $\mathrm{HA}$ reduces this potassium current is not yct known. However, previous biochemical studies have shown that stimulation of $\mathbf{H}_{1}$-receptors in many cell types, including in guinea pig brain, results in a

\section{A}

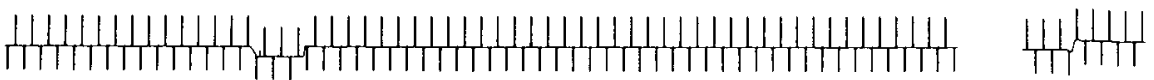
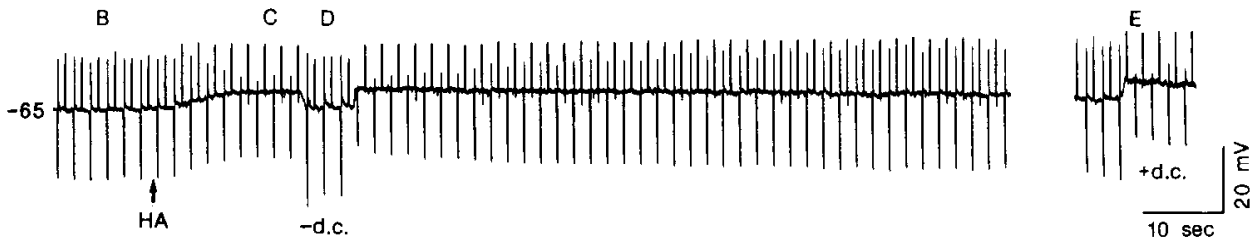

B

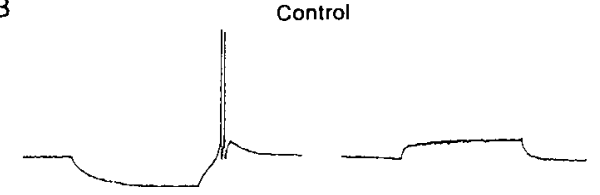

D

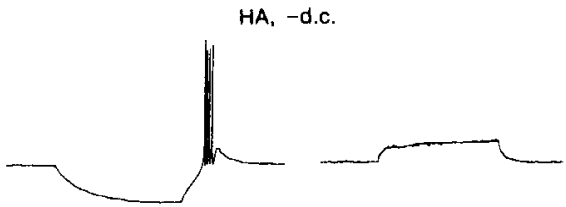

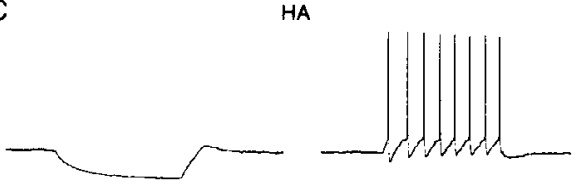

E

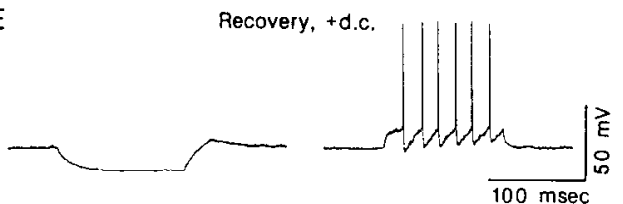

Figure 9. Effects of HA-induced slow depolarization on the response to hyperpolarizing and depolarizing current pulses in a guinea pig LGNd neuron. Intracellular injection of a hyperpolarizing current pulse at resting membrane potential $(-65 \mathrm{mV})$ results in a rebound $\mathrm{Ca}^{2+}$ spike and associated burst discharge (expanded in $B$ for detail). Injection of a depolarizing current pulse is subthreshold for the generation of action potentials $(B)$. Application of HA results in a slow depolarization and inhibits the rebound burst discharge following the hyperpolarizing pulse $(C, H A)$ but enhances the response to the depolarizing current pulse to the generation of eight action potentials $(C, H A)$. Compensation for the slow depolarization with the intracellular injection of current reverses these effects and reveals a substantial decrease in apparent input conductance $(A ; D, H A$ and $-d . c$.). The ability of HA to shift the responsiveness of LGNd neurons appears to result largely from the slow depolarization, since similar depolarizations after recovery with the intracellular injection of current have a similar effect $(A ; E,+d . c$.). The responses of the neuron to the hyperpolarizing and depolarizing current pulses in $A$ are expanded in $B-E$ for detail, as indicated. 
A

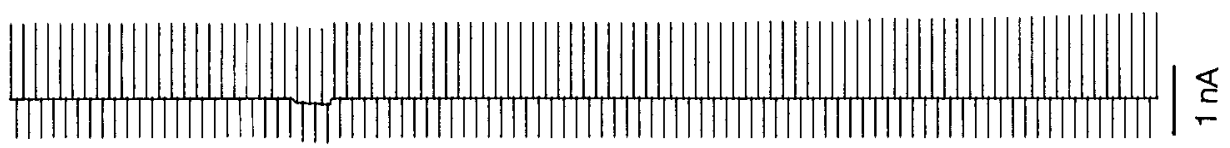

B

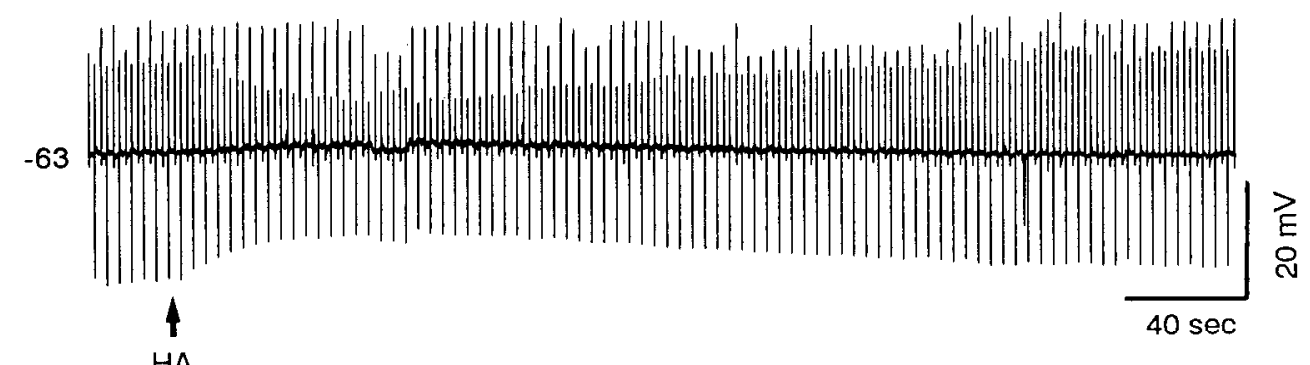

B

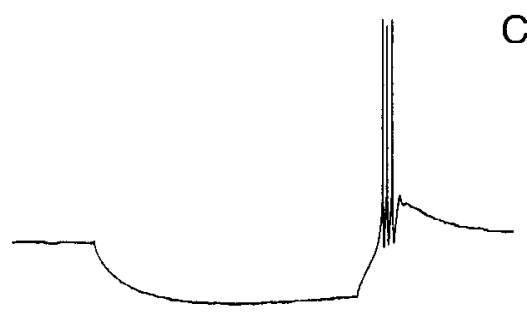

Control

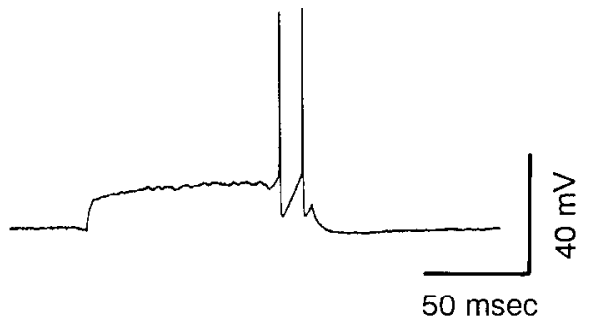

C

HA

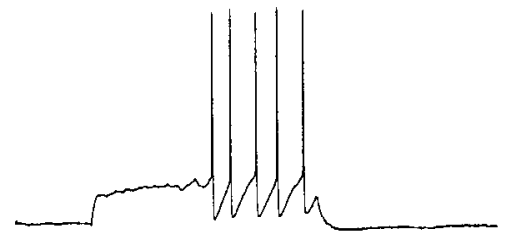

Figure 10. Modulation of thalamic neuronal excitability through stimulation of $\mathrm{H}_{2}$-receptors with HA. $A$, Application of HA into a cat LGNd neuron at $-63 \mathrm{mV}$ while injecting hyperpolarizing and depolarizing current pulses results in the typical small depolarization and increase in apparent input conductance. The subsequent reduction in the amplitude of the hyperpolarizing current pulse reduces the amplitude of the rebound $\mathrm{Ca}^{2+}$ spikemediated burst (compare $B$ and $C$ ). In contrast, the responsc to the depolarizing current pulse is mildly enhanced (compare $B$ and $C$ ). Pyrilamine ( $1 \mu \mathrm{M}$ ) was included in the bathing medium to block $\mathrm{H}_{1}$-receptors. marked increase in inositol phospholipid turnover and production of inositol phosphates such as $\mathrm{IP}_{3}$ (Daum et al., 1983, 1984). Interestingly, the other receptors that we have demonstrated to be coupled to suppression of $I_{\mathrm{KL}}$, namely $\alpha_{1}$-adrenergic, muscarinic, and 5- $\mathrm{HT}_{2}$ serotoninergic (McCormick and Prince, 1987, 1988; McCormick and Wang, 1991), are all known to stimulate inositol phospholipid turnover upon receptor activation (reviewed in Nishizuka, 1984). The possibility that production of an inositol phospholipid may be the common path by which these receptors decrease $I_{\mathrm{KL}}$ remains to be examined.

The small depolarization and increase in apparent input conductance mediated by $\mathrm{H}_{2}$-receptors appear to be mediated by an enhancement of the hyperpolarization-activated cation current $I_{h}$. This enhancement results from a shift in voltage sensitivity of $I_{h}$ to more positive membrane potentials such that at any given voltage between -60 and $-90 \mathrm{mV}$, the amount of $I_{h}$ active at steady state is increased. Thus, at resting membrane potentials $(-65$ to $-70 \mathrm{mV})$, activation of $\mathrm{H}_{2}$-receptors results in an increase in the amount of $I_{h}$ active, resulting in an increase in resting membrane conductance and a small depolarization toward the equilibrium potential for $I_{h}(-43 \mathrm{mV}$; McCormick and Pape, 1990a). Since this current is activated by hyperpolarization and the equilibrium potential is depolarized from resting membrane potential, this enhancement of $I_{h}$ results in a strong reduction in the response of the neuron to hyperpolarizing current pulses, while the ability of depolarizing current pulses to generate action potentials is slightly enhanced (McCormick and Pape, 1990b). The second-messenger system through which
HA enhances $I_{h}$ is not yet known, although $\mathrm{H}_{2}$-histaminergic receptors have previously been shown to be coupled to stimulation of adenylyl cyclase in many different cell types, including in guinea pig thalamus (Rogers et al., 1975; Schwartz et al., 1986). We have previously shown that direct activation of adenylyl cyclase with forskolin results in a marked enhancement of $I_{h}$ while control applications of the inactive forskolin analog 1,9-dideoxy forskolin are without effect (McCormick and Pape, 1990b). Similarly, direct increases in intracellular levels of cAMP through the application of the membrane-permeable cAMP analog 8-bromo-cAMP also result in a marked enhancement of $I_{h}$, as does reduction of cAMP breakdown through the use of the phosphodiesterase inhibitor IBMX (McCormick and Pape, $1990 \mathrm{~b}$ ). The ability of HA to increase cAMP levels in guinea pig thalamus (Rogers et al., 1975) together with the findings that increases in cAMP levels enhance $I_{h}$ strongly suggests that HA is enhancing this current through activation of adenylyl cyclase. One possible experiment to test this hypothesis is to block the activation of cAMP-dependent protein kinases through specific inhibitors such as WIPTIDE (Cheng et al., 1986) and test whether HA is still capable of enhancing $I_{h}$.

\section{Functional consequences of activation of histaminergic receptors}

Thalamic relay neurons have two distinct modes of action potential generation: high-frequency burst firing and single-spike activity (Jahnsen and Llinás, 1984a,b; Steriade and Deschênes, 1984). High-frequency burst firing, prevalent during periods of 
slow-wave sleep and drowsiness, appears as a discharge of two to eight $\mathrm{Na}^{+} / \mathrm{K}^{+}$-dependent action potentials at an interspike frequency of $300-500 \mathrm{~Hz}$ and is mediated by the occurrence of a low-threshold $\mathrm{Ca}^{2+}$ spike mediated by the transient $\mathrm{Ca}^{2+}$ current $I_{7}$ (Jahnsen and Llinás, 1984a,b; Coulter et al., 1989; Hernandez-Cruz and Pape, 1989). High-frequency burst discharges occur naturally in vivo and in vitro in a number of different manners, including as highly stereotyped $1-4 \mathrm{~Hz}$ rhythmic burst firing (McCormick and Pape, 1990a), as 7-12 Hz rhythmic spindle waves (Steriade and Deschênes, 1984), or as isolated events occurring either spontaneously or in response to visual stimuli (Fourment et al., 1984; Lu et al., 1990). Depolarization of thalamic neurons, such as that which occurs during awakening from slow-wave sleep (Hirsch et al., 1983), abolishes high-frequency burst firing through inactivation of $I_{T}$, switches the neuron to the single-spike mode of action potential generation, and greatly increases the ability of the neuron to transmit sensory information faithfully (Livingstone and Hubel, 1981; McCormick and Feeser, 1990).

The possibility that HA contributes to the switch in firing mode of thalamic relay neurons during changes in arousal is supported by the electrophysiological actions of this putative neurotransmitter reported here. Reduction of $I_{K L}$ by $H A$ acting through $\mathrm{H}_{1}$-receptors can result in a $5-20 \mathrm{mV}$ depolarization of LGNd relay neurons and can change their electroresponsiveness from one of generating rebound burst discharges and a relative lack of single-spike activity, to one of generating predominantly single-spike activity and a relative lack of rebound burst discharges (Fig. 9), thereby mimicking the same transition known to occur naturally during increases in arousal and upon awakening from slow-wave slccp (Hirsch ct al., 1983; McCarlcy ct al., 1983). The possibility that endogenous release of HA may result in a similar slow depolarization is supported by the finding that local electrical activation of axons in the LGNd slice results in a slow EPSP that is nonadditive with maximal stimulation of histaminergic receptors and that is reduced in amplitude by block of $\mathrm{H}_{1}$-histaminergic receptors (Feeser et al., 1989; McCormick, unpublished observations). In addition to the slow depolarizing effect of HA, enhancement of $I_{h}$ through activation of $\mathrm{H}_{2}$-receptors will decrease the ability of thalamic neurons to burst rhythmically due to reduction in response to hyperpolarizing inputs (Fig. 10). In support of a role of histaminergic systems in the control of arousal, central administration of HA results in electrophysiological indications of arousal (Monnier et al., 1970; Kalivas, 1982; Tasaka et al., 1989), while central or peripheral administration of $\mathrm{H}_{1}$-antagonists results in incrcases in drowsiness and slow-wave sleep (Wauquier et al., 1981; Lin et al., 1988). Indeed, the main ingredient in many of the over-the-counter sleeping aids sold in the United States is an $H_{1}$-antagonist, diphenhydramine (Douglas, 1980). Inactivation of the histaminergic neurons in the hypothalamus through local application of the potent $\mathrm{GABA}_{\mathrm{A}}$ agonist muscimol results in marked decreases in arousal and an increase in slow-wave sleep (Lin et al., 1989). Extracellular single-unit recordings from presumed histaminergic neurons within the tuberomammillary nucleus reveal that these neurons fire at relatively low frequencies $(0-10 \mathrm{~Hz})$ in a relatively regular fashion that, on average, increases in frequency in anticipation of increases in arousal and the transition from slow-wave sleep to waking (Vanni-Mercier et al., 1984; Reiner and McGeer, 1987).

Together, these effects of HA will facilitate a change of thalamic neuronal activity from one of endogenous oscillation and poor responsiveness to sensory inputs, to one dominated by single-spike activity and a more accurate and faithful relay of sensory information. Further processing of sensory information in the neocortex will also be facilitated by increased release of HA through the reduction of spike frequency adaptation in cortical pyramidal cells resulting from a block of the slow $\mathrm{Ca}^{2+}$ activated $\mathrm{K}^{+}$current $I_{\mathrm{AHP}}$ through stimulation of $\mathrm{H}_{2}$-histaminergic receptors (Haas and Greene, 1986; McCormick and Williamson, 1989). In this manner, the hypothalamic histaminergic system may make an important contribution to the ascending control of arousal, sensory information processing, and cognition.

\section{References}

Airaksinen MS, Panula P (1988) The histaminergic system in the guinea pig central nervous system: an immunocytochemical mapping study using an antiserum against histamine. J Comp Neurol 273:163186.

Andrade R, Malenka RC, Nicoll RA (1986) A G-protein couples serotonin and $\mathrm{GABA}_{\mathrm{B}}$ receptors to the same channels in hippocampus. Science 234:1261-1265.

Bouthenet ML, Ruat M, Sales N, Garbarg M, Schwartz JC (1988) A detailed mapping of histamine $\mathrm{H}_{1}$-receptors in guinea-pig central nervous system established by autoradiography with [125I]iodobolpyramine. Neuroscience 26:553-600.

Cheng HC, Kemp BE, Pearson RB, Smith AJ (1986) A potent synthetic peptide inhibitor of the CAMP-dependent protein kinase. J Biol Chem 261:989-992.

Coulter DA, Huguenard JR, Prince DA (1989) Calcium currents in rat thalamocortical relay neurones: kinetic properties of the transient, low-threshold current. J Physiol (Lond) 414:587-604.

Daum PR, Downes CP, Young JM (1983) Histamine-induced inositol phospholipid breakdown mirrors $\mathrm{H}_{1}$-receptor density in brain. Eur $\mathrm{J}$ Pharmacol 87:497-498.

Daum PR, Downes CP, Young JM (1984) Histamine stimulation of inositol 1-phosphate accumulation in lithium-treated slices from regions of guinea pig brain. J Neurochem 43:25-32.

Douglas WW (1980) Histamine and 5-hydroxytryptamine (serotonin) and their antagonists. In: The pharmacological basis of therapeutics (Goodman HA, Goodman LC, Gilman A, eds), pp 609-646. New York: Macmillan.

Feeser HR, Pape H-C, McCormick DA (1989) Physiological characteristics of a very slow excitatory post-synaptic potential in the LGNd. Soc Neurosci Abstr 15:1310.

Fourment A, Hirsch JC, Marc ME, Guidet C (1984) Modulation of postsynaptic activities of thalamic lateral geniculate neurons by spontaneous changes in number of retinal inputs in chronic cats. 1 . Inputoutput relations. Neuroscience 12:453-464.

Haaksma EEJ, Leurs R, Timmerman H (1990) Histamine receptors: subclasses and specific ligands. Pharmacol Ther 47:73-104.

Haas HL, Greene RW (1986) Effects of histamine on hippocampal pyramidal cells of the rat in vitro. Exp Brain Res 62:123-130.

Hernandez-Cruz A, Pape HC (1989) Identification of two calcium currents in acutely dissociated neurons from the rat lateral geniculate nucleus. J Neurophysiol 61:1270-1283.

Hirsch JC, Fourment A, Marc ME (1983) Sleep-related variations of membrane potential in the lateral geniculate body relay neurons of the cat. Brain Res 259:308-312.

Jahnsen H, Llinás R (1984a) Electrophysiological properties of guineapig thalamic neurones: an in vitro study. J Physiol (Lond) 349:205226.

Jahnsen H, Llinás R (1984b) Ionic basis for the electroresponsiveness and oscillatory properties of guinea-pig thalamic neurones in vitro. $\mathbf{J}$ Physiol (Lond) 349:227-247.

Kalivas PW (1982) Histamine-induced arousal in the conscious and pentobarbital-pretreated rat. J Pharmacol Exp Ther 222:37-42.

Lin J-S, Luppi P-H, Salvert D, Sakai K, Jouvet M (1986) Histaminecontaining neurons in cat hypothalamus. C R Acad Sci (Paris) Ser III 9:371-376.

Lin J-S, Sakai K, Jouvet M (1988) Evidence for histaminergic arousal mechanisms in the hypothalamus of cat. Neuropharmacology 27:111122. 
Lin JS, Sakai K, Vanni-Mercier G, Jouvet M (1989) A critical role of the posterior hypothalamus in the mechanisms of wakefulness determined by microinjection of muscimol in freely moving cats. Brain Res 479:225-240.

Livingstone MS, Hubel DH (1981) Effects of sleep and arousal on the processing of visual information in the cat. Nature 291:554-561.

Lu S-M, Guido W, Shermian SM (1990) Low threshold calcium spikes in LGN cells during responses to visual stimuli. Soc Neurosci Abstr 16:159.

McCarley RW, Benoit O, Barrionuevo G (1983) Lateral geniculate unitary discharge in sleep and waking: state- and rate-specific aspects. J Neurophysiol 50:798-818.

McCormick DA (1989) Cholinergic and noradrenergic modulation of thalamocortical processing. Trends Neurosci 12:215-221.

McCormick DA, Feeser HR (1990) Functional implications of burst firing and single spike activity in lateral geniculate relay neurons. Neuroscience 39:103-113.

McCormick DA, Pape H-C (1990a) Properties of a hyperpolarizationactivated cation current and its role in rhythmic oscillation in thalamic relay neurones. J Physiol (Lond) 431:291-318.

McCormick DA, Pape H-C (1990b) Noradrenergic and serolonergic modulation of a hyperpolarization-activated cation current in thalamic relay neurones. J Physiol (Lond) 431:319-342.

McCormick DA, Prince DA (1987) Actions of acetylcholine in the guinea-pig and cat medial and lateral geniculate nuclei, in vitro. $\mathrm{J}$ Physiol (Lond) 392:147-165.

McCormick, DA, Prince DA (1988) Noradrenergic modulation of firing pattern in guinea pig and cat thalamic neurons, in vitro. J Neurophysiol 59:978-996.

McCormick DA, Wang Z (1991) Serotonin and noradrenaline excite GABAergic neurones of the guinea pig and cat nucleus reticularis thalami. J Physiol, in press.

McCormick DA, Williamson A (1989) Convergence and divergence of neurotransmitter action in human cerebral cortex. Proc Natl Acad Sci USA 86:8098-8102.

Monnier M, Sauer R, Hatt AM (1970) The activating effect of histamine on the central nervous system. Int Rev Neurobiol 12:265305.
Nishizuka $Y$ (1984) Turnover of inositol phospholipids and signal transduction. Science 225:1365-1370.

Panula P, Pirvola U, Auvinen S, Airaksinen MS (1989) Histamineimmunoreactive nerve fibers in the rat brain. Neuroscience 28:585610.

Panula P, Airaksinen MS, Pirvola U, Kotilainen E (1990) A histaminecontaining neuronal system in human brain. Neuroscience $34: 127-$ 132.

Pape H-C, McCormick DA (1989) Noradrenaline and serotonin selectively modulate thalamic burst firing by enhancing a hyperpolarization-activated cation current. Nature 340:715-718.

Reiner PB, McGeer EG (1987) Electrophysiological properties of cortically projecting histamine neurons of the rat hypothalamus. Neurosci Lett 73:43-47.

Rogers M, Dismukes K, Daly JW (1975) Histamine-elicited accumulations of cyclic adenosine $3^{\prime}, 5^{\prime}$-monophosphate in guinea-pig brain slices: effect of $\mathrm{H}_{1}$ - and $\mathrm{H}_{2}$-antagonists. J Neurochem 25:531-534.

Ruat M, Traiffort E, Bouthenet ML, Schwartz JC, Hirschfeld J, Buschauer A, Schunack W (1990) Reversible and irreversible labeling and autoradiographic localization of cerebral histamine $\mathrm{H}_{2}$ receptor using [25I]iodinated probes. Proc Natl Acad Sci USA 87:1658-1662.

Schwartz J-C, Garbarg M, Pollard H (1986) Histaminergic transmission in the brain. In: Handbook of physiology, Vol IV, The nervous system, pp 257-316. Bethesda, MD: American Physiological Society.

Steriade M, Deschênes M (1984) The thalamus as a neuronal oscillator Brain Res Rev 8:1-63.

Steriade M, Llinas RR (1988) The functional states of the thalamus and the associated neuronal interplay. Physiol Rev 68:649-742.

Tasaka K, Chung YH, Sawada K, Mio M (1989) Excitatory effect of histamine on the arousal system and its inhibition by $\mathrm{H}_{1}$ blockers. Brain Res Bull 22:271-275.

Vanni-Mercier G, Sakai K, Jouvet M (1984) "Waking state specific" neurons in the caudal hypothalamus of the cat. C R Acad Sci (Paris) Ser III 298:195-220.

Wauquier A, Van Den Broeck WAE, Awouters F (1981) A comparison between astemizole and other antihistamines on sleep-wakefulness cycles in dogs. Neuropharmacology 20:853-859. 